\title{
CAPABILITY BUILDING AND LEARNING: AN EMERGENT BEHAVIOR APPROACH
}

\author{
Rafael Andreu \\ Josep Riverola \\ Josep Ma Rosanas \\ Rafael De Santiago
}




\title{
CAPABILITY BUILDING AND LEARNING: AN EMERGENT BEHAVIOR APPROACH
}

\author{
Rafael Andreu ${ }^{1}$ \\ Josep Riverola ${ }^{2}$ \\ Josep Ma Rosanas ${ }^{3}$ \\ Rafael De Santiago ${ }^{4}$
}

\section{Abstract}

Economics-based models typically overlook management decisions and firms' capabilities. We develop a model that puts firms at center stage by simulating the aggregate behavior of a population of firms resulting from specific management decisions. The model features a learning process that produces changes in companies' capabilities. Decisions are made under imperfect information and bounded rationality, and managers may sacrifice short-term performance in exchange for qualitative variables that affect their firm's future potential. The model provides a structured setting in which these issues - often discussed only in an informal way - can be more rigorously analyzed. The simulations produce a variety of hard-to-anticipate emergent behaviors. Economic performance appears to be quite sensitive to managers' estimates of the true capabilities of their own firms. Also, companies that are willing to accept sacrifices in the short run in order to increase future potential appear to be more stable than the rest.

Keywords: Capability building vs. economic performance, imperfect information, learning, bounded rationality.

\footnotetext{
${ }^{1}$ Professor, Strategic Management and Information Systems Departments, IESE

${ }^{2}$ Emeritus Professor, Production, Technology and Operations Management Department, IESE

${ }^{3}$ Professor, Accounting and Control Department, IESE

${ }^{4}$ Associate Professor, Managerial Decision Sciences Department, IESE
} 


\section{CAPABILITY BUILDING AND LEARNING: AN EMERGENT BEHAVIOR APPROACH}

\section{Introduction}

Conventional economic models assume that firms have identical production functions, that their efficiency improves at the same pace, and that managers are rational, have complete information, and maximize profits. With these assumptions microeconomic theory shows that profit maximization (or, in modern terms, firm value maximization) also achieves maximum social welfare (see Jensen (2000) for a brief statement of the argument).

The profit maximization hypothesis has been severely criticized as being "too difficult, unrealistic and immoral" (Anthony 1960), as have been formulations based on maximizing firm value. According to Senge, by maximizing profit in the short run one is liable to ignore complex feedback dynamics. "This is why manipulating profits over the short-term is much easier than building wealth over the long term. Thus, whether intentionally or not, firm value maximization will almost always become, by default, short-term profit maximization" (Senge 2000). Simon (1983) calls the maximizing approach "the Olympian model", which serves perhaps "as a model of the mind of God, but certainly not as a model of the mind of man". Canals (2010) shows the limitations of the value maximization approach from the point of view of implementation and achievability. Jack Welch, who popularized the notion of shareholder value in the 1980s, said in 2009 that this was "a dumb idea" and that value maximization is "a result, not a strategy" (Welch 2009). Analysts have tried to take qualitative factors (such as quality and depth of management, or strategic credibility) into account, but they recognize that "the information on strategic plans and planning provided by management is of generally low quality” (Chugh and Meador 1984).

The need for a better approach to firms and their relationship with the environment is clearly felt, especially in a post-crisis world (Zollo and Freeman 2010). However, dropping the traditional (economics-based) assumptions to make models more realistic complicates the analysis and is seldom done, thus leaving management action out of the picture.

In this paper we depart from these conventional assumptions by analyzing how management decisions affect the time-wise performance of companies when firms can develop their own capabilities. By having a number of companies develop in parallel, we estimate their average transient behavior. In our model, managers decide what projects to undertake, being aware that different projects will contribute in different ways to learning, capability building, and 
eventually to firm performance. This allows us to explore in detail how management decisions affect the trade-off between short and long-term objectives (in a way reminiscent of the classical distinction between exploration and exploitation, cf. March (1991)) and the effect of different forms of learning and knowledge accumulation with time, both in firms and in management, as aggregate information about how projects contribute to the economy's performance becomes "publicly available".

The paper is organized as follows: Section 2 overviews the model's most relevant features (a formal description is presented in the appendices); Section 3 describes the simulation strategy used; Section 4 identifies several cases of emergent behavior; in Section 5 we discuss managerial implications of our findings; and Section 6 presents the conclusions, analyzes the limitations of the model, and puts forward suggestions for further research.

\section{Model overview}

Our model focuses on the evolution of a population of independent firms over an arbitrary number of time periods. Firms do not compete among themselves. They should be considered a sample that allows the computation of population-based expectations when the system is not in steady state ${ }^{1}$. Firms have "profiles", which are determined by whether or not they possess certain capabilities. These profiles evolve over time as companies acquire or lose capabilities. At the beginning of each time period, and in all companies independently, firms' managers chose which project to undertake. They do so with two potentially conflicting goals in mind: on the one hand, they seek economic results; on the other, they seek to develop a "better" profile for their firm, so that the firm is able to undertake more demanding projects in the future.

By "better" profiles we mean profiles that are more in line with managers' preferences. This is done in the following way. Managers have their own preferences regarding the ideal type of firm they would eventually like to have. When deciding whether to accept a project or not, managers consider how the project fits the firm's current profile and also how undertaking the project could result in learning that will bring the firm closer to the managers' ideal firm profile. Capability building has been discussed in the context of the resource-based view of the firm (Wernerfelt 1984, Amit and Shoemaker 1993, Barney 1991, Dierickx and Cool 1989, Teece et al. 1990), including the role of management in the learning process (Andreu and Ciborra 1996). Argawal and Helfat (2009) explain that capability development has enough potential "to substantially affect (a firm's) long-term prospects." The next section and the appendices describe how this is implemented.

In order to make the model more realistic, we include bounded rationality in the managers' decision-making process, as well as imperfect information. By bounded rationality we mean that, when choosing projects, managers do not identify the project that is best in terms of their objectives but, rather, are satisfied when they find a project that is "good enough". While an "optimizing" decision rule (evaluating all candidate projects and choosing the best one) is at one extreme of the spectrum, choosing the first project that comes is at the other extreme. By setting an acceptance threshold, we control how "demanding" (how close to optimizing) managers are.

\footnotetext{
${ }^{1}$ Because of this, one cannot appeal to the ergodic theorems to get long-run averages by computing the average along a single path. 
The "imperfect information" assumption is modeled in the following twofold way:

1) Managers do not have perfect knowledge of the actual capabilities (the true profile) of their own firms. (This captures the idea that it is hard to know the true state of an organization.) Instead, managers have a prior probability distribution over all possible profiles and this prior is updated as managers observe the company's results. For instance, managers may choose to undertake a project because they think the company has some capability; once they see the project's results, however, they may realize that the firm probably does not have that capability. This leads managers to update their beliefs about the company's profile.

2) Managers' imperfect knowledge regarding how likely the firm is to achieve economic success when undertaking a project is modeled through probability distributions estimated from aggregate information available in the sample.

Treating the dynamic evolution of a firm under the above conditions analytically is very complicated. Most of the well known tools are inadequate for this purpose. We therefore resort to simulation techniques in order to systematically explore the model's transient behavior. Simulation has been successfully used in management research and economic dynamics; for example, by Davis et al. (2007, 2009), Harrison et al. (2007), Gilbert (2008), Miller and Page (2007), and Coen and Maritan (2011).

One characteristic of the resulting model is that the interplay between capability building, learning, bounded rationality, and uncertainty results in difficult-to-anticipate "emergent behavior", in which transient phenomena are often more informative than the final state achieved by the economy. "Emergent behavior" happens when simple rules can expand into sophisticated behavior that cannot be attributed to any individual agent, but rather to the global system structure. It appears when a number of agents interact with each other without a central planner and generate complex conducts that are not explicitly "programmed" in the simple rules. Emergent behavior is hard to predict because the number of interactions increases in a combinatorial way with the number of agents, often making it impossible, even for a computer, to exhaustively examine all the system potential states, thus allowing unexpected types of behavior to emerge (see, for example, Gilbert (2008)).

The remainder of this section describes how the model actually works.

\section{Firm Profiles}

We characterize firms according to whether they have, or lack, a set of capabilities that consists of Unity (U), Attractiveness (A) and Effectiveness (E). In the model's current implementation the only conceptual difference between $\mathrm{U}, \mathrm{A}$ and $\mathrm{E}$ is that we impose a "probabilistic hierarchy" on them, meaning that $U$ is harder to develop ("learn") than A, which is in turn harder than E. Also, $\mathrm{U}$ may be more easily lost than A, which may be more easily lost than E (see Appendix 1).

We thus denote a firm's profile by the triplet (U, A, E), where variables $\mathrm{U}, \mathrm{A}$, and $\mathrm{E}$ indicate whether the firm has the related capability or not. If it does, the variable is set to 1 , while if it does not, the variable is set to 0 . For example, profile $(0,1,1)$ indicates that the company has attractiveness and effectiveness but lacks unity.

We use "all or nothing" levels for the capabilities for several reasons. First, subdividing a single level into $\mathrm{N}$ levels seems to lead to very similar behavior. Second, using $\mathrm{N}$ levels requires the 
specification of a transition law, the evolution dynamics, with at least $\mathrm{N}$ times more probabilities. Finally, the abstract nature of the capabilities makes it difficult to characterize each level in terms of its properties, and therefore in terms of its transition probabilities. It is easy to split a single transition probability into $\mathrm{N}$ parts, but it does not add much. We therefore preferred the binary description.

While carrying out a project, a company's profile may change as a result of learning. If at the beginning of period $t$ a company's profile is $(1,0,1)$ and by period $t+1$ its new profile is $(1,1,1)$, this means that it has gained attractiveness. If, instead, the new profile is $(0,0,1)$, the company has lost unity. If the new profile is unchanged $(1,0,1)$, no learning has occurred. Below we explain in more detail how profile changes are modeled ${ }^{2}$.

\section{Project Types}

Project types are specified in terms of the same three capabilities as company profiles, and are also represented as (U, A, E) triplets. All project types require a combination of the three capabilities. The fact that a project type requires a particular capability is to be understood in two complementary ways. First, a firm that has the capability required for a particular project type has a better chance of succeeding in that project type than a firm that lacks the required capability. Second, a firm that does not have the capability required for a particular project type but nevertheless undertakes that type of project may acquire the required capability. Conversely, a company that has a particular capability may maintain that capability even when undertaking a type of project for which the capability is not required.

The learning process that leads to changes in a company's profile is therefore probabilistic. For example, if a firm has a $(0,0,1)$ profile and its managers would like to develop attractiveness and unity, they can try to do so by choosing a project that requires such capabilities - a $(1,1,1)$ project, say - hoping that, in the process of carrying out the project, workers will learn. We set the probabilities by enforcing the abovementioned "probabilistic hierarchy", i.e., setting the probability of "learning" (E)ffectiveness higher than that of acquiring (A)ttractiveness, and the probability of "learning" (A)ttractiveness higher than that of acquiring (U)nity. Also, since we assume (U)nity to be easier to lose than (A)ttractiveness, we also set the probabilities accordingly. A detailed account of how this is done in terms of the model parameters is given in Appendix 1.

\section{Project Evaluation}

Managers use two criteria to evaluate and choose projects. On the one hand, they consider a project's economic value. This is a "rational", short-term, purely financial criterion. As a proxy we use the project's probability of success. Note that success coincides with the expected return if we assume, without much loss of generality, that every project has a unit margin.

On the other hand, managers consider capabilities as an intangible asset which, if developed, will enable the company to succeed in projects that it could not have succeeded in otherwise. Trying to develop capabilities is a more long-run oriented and "aspirational" criterion in the sense that it depends on the type of company managers aspire to have in the future.

\footnotetext{
${ }^{2}$ Since we treat the three profiles as probabilistically independent, one could simulate each profile separately instead of aggregating them in triplets. In our view, however, this would make the model more difficult to understand.
} 
Generally speaking, managers are interested in developing capabilities through learning because it gives their companies a better chance of future success. However, if developing capabilities requires giving up short-term objectives in order to make long-term goals more likely, there may be trade-offs.

Given a specific project, we model these trade-offs as follows. Based on managers' estimates, we compute: (i) A proxy for the probability that the company will succeed in the project; (ii) A proxy for the probability that the company will acquire or maintain (through learning) each capability (see Appendix 2 for details). We then combine these two proxies linearly, as depicted in Figure 1, where the parameter $\alpha$ (a value between 0 and 1, which we call "Sacrifice") is the weight assigned to the proxy that accounts for the learning potential. The closer $\alpha$ is to 1 , the more willing managers are to forego immediate performance in order to develop future capabilities. When $\alpha$ is zero, managers try to maximize financial results only.

\section{Figure 1}

Project evaluation procedure

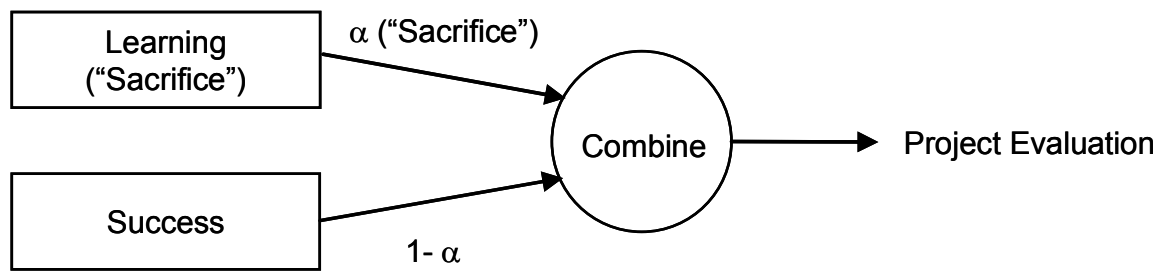

\section{Project Selection}

An important feature of the model is that managers choose projects with bounded rationality. There are many ways of implementing bounded rationality (Rubinstein 1998). Perhaps the simplest one is Simon's (1955) original formulation, schematically depicted in Figure 2. Bounded rationality is implemented by setting a threshold for the project's value. There is no need to evaluate all the projects; the first project that exceeds the threshold is selected. The order in which a firm evaluates projects is important for the firm's development. Initially, we have chosen a random order. Changing it, however, is an option of the current implementation.

\section{Figure 2}

Bounded rationality in project selection based on a threshold value

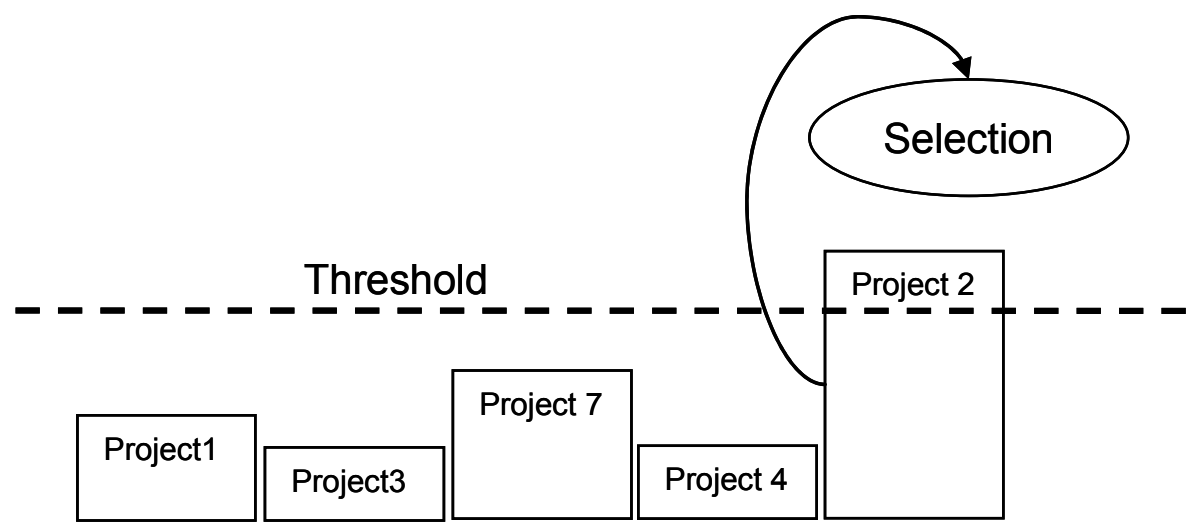




\section{Influence of projects on firms' learning}

One of the consequences of executing a project is that the firm's profile may change (the firm "learns"). In order to avoid simple deterministic patterns, we assume that management decisions do not necessarily lead to the same results, even if they take place at the same moment in time and in the same place ${ }^{3}$.

We thus assume that firm profiles evolve through probabilistic transitions. Figure 3 summarizes the logic of the corresponding probabilities for the case of (A)ttractiveness (the logic is analogous for the other two capabilities). Part (a) illustrates how transitions occur if the chosen project has (A)ttractiveness; part (b) shows the transitions when the project does not have it.

\section{Figure 3}

(a) Transition probabilities when the chosen project has attractiveness.

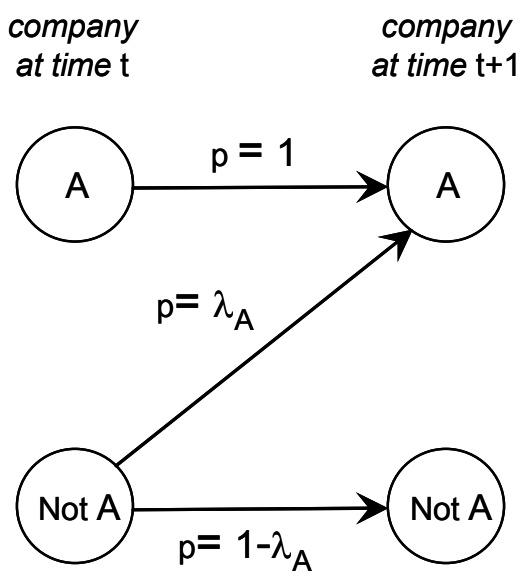

(b) Transition probabilities when the chosen project does not have attractiveness.

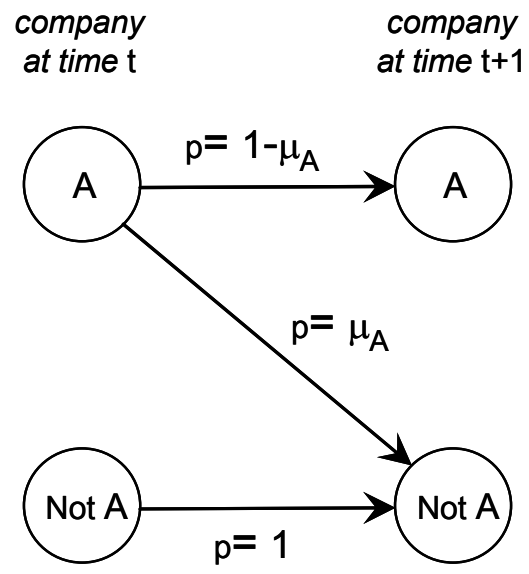

Thus, as Figure 3a shows, if a firm with a certain capability undertakes a project that also has such attribute, the firm maintains the capability with probability 1 (no change). If a firm without the capability undertakes such a project, it will develop the capability with probability $\lambda_{\mathrm{A}}$, or not develop it with probability $1-\lambda_{\mathrm{A}}$. (The equivalent probability for (E)ffectiveness is named $\lambda_{\mathrm{E}}$ and for (U)nity $\lambda_{\mathrm{U}}$.).

Conversely, in Figure 3b, if a firm that lacks a certain capability undertakes a project that lacks that capability, the company will continue to lack the capability with probability 1 . If a firm that has a certain capability undertakes a project that does not have it, the firm will lose that capability with probability $\mu_{\mathrm{A}}$ or keep it with probability $1-\mu_{\mathrm{A}}$. As above, $\mu_{\mathrm{E}}$ and $\mu_{\mathrm{U}}$ are the corresponding probabilities for (E)ffectiveness and (U)nity.

\footnotetext{
${ }^{3}$ Without randomness, the model's behavior would be rather simple and uninteresting. For instance, a deterministic evolution in a $\{0,1\}$ space only allows transitions that either always go to 0 , or always go to 1 . This results in four types of transitions. In addition, the time to reach a state is either 0 or 1 steps, which is not a very exciting behavior! In a deterministic scenario, all companies would evolve in the same way if they happened to start in the same state (picking the same projects and undergoing the same changes in profiles).
} 
Further learning in the model takes place in the following two areas:

1) Managers learn about the success potential of different projects when undertaken by firms with different profiles by observing the aggregate information regarding past performance that becomes available.

2) Managers refine their (imperfect) knowledge about the true profiles of their companies, using success information about the projects undertaken.

The first type of learning is an example of "rote learning", which is the simple accumulation of information directly from the environment. The second type may be called "reasoned or logical learning"; it is based on the ability to change one's beliefs about the world as observations are collected, interpreted, and assimilated.

Rote learning (Klein 1996) follows from simple observation of a random phenomenon, even if its probabilistic structure is unknown. We implement it by means of a neural network, NN (Haykin 2009) ${ }^{4}$, thus assuming that the "brain" of the decision maker can be modeled as a NN that estimates the success probability of different projects by observing a series of successes and failures in the real world.

Logical learning is implemented in the model by successively updating managers' prior probability distributions over profiles, using Bayes' Rule (see Appendix 2). We thus assume that managers can change their initial beliefs by observing a piece of information. Although a manager may not know how to apply Bayes' rule explicitly, it has been shown that quick and dirty reasoning based on logical Bayes-like rules is often used to anticipate the value of a random phenomenon (Pearl 1998).

\section{Simulation Structure and Strategy of Analysis}

This section presents the structure of the discrete-time simulation program that we have developed for experimenting with the model described above. ${ }^{5}$ An overview of its structure is depicted in Figure 4.

The initial step requires the modeler to: (i) set the value of the basic parameters that will remain unchanged throughout the simulation, such as the transition probabilities $\lambda$ and. $\mu$, the threshold, and the sacrifice parameter $\alpha$; (ii) provide the parameters to generate a number of firms, each endowed with a set of capabilities, managers' preferences, managers' initial knowledge about the true profile of their own firm, and so on. ${ }^{6}$

\footnotetext{
${ }^{4}$ A neural network is an object with exogenous inputs and outputs. Some of the inputs and all the outputs are used for learning. They are supplied with the actual data and result of an experiment, and the internal structure of the network is modified to provide the best fit for the new observation. Whenever a prediction is needed, inputs are supplied and the network uses its internal structure to compute the prediction. The internal structure is essentially a nonlinear least squares model, recalculated for each new piece of evidence. The same least squares structure provides the computational machinery for the prediction.

${ }^{5}$ See Appendix 2 for a detailed description of the model. The software we use has been written in Delphi, an objectoriented programming language, and has roughly 5000 sentences.

${ }^{6}$ We normally generate 1,000 companies, as this is sufficient to obtain a significant sample without slowing down the process. Changing the number of companies can be easily done. In our experience, good quality results can be obtained with as few as 300 firms.
} 


\section{Figure 4}

Overall structure of the simulation program

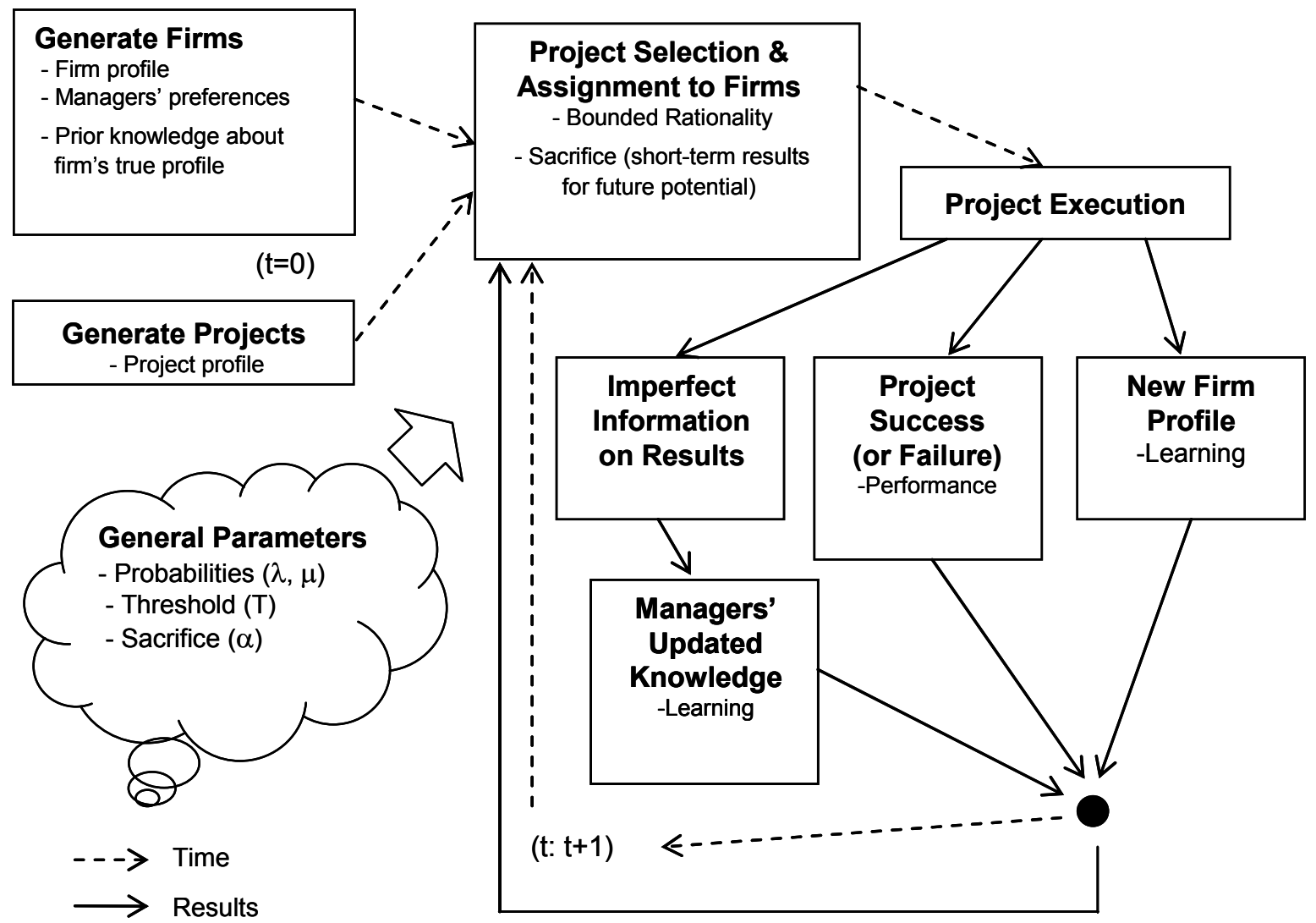

At each discrete step of the run, each firm selects a project and then executes it. Next, the results (success or failure, effects on each firm's profile) are collected. These results are used to update: (i) managers' knowledge about the true profile of their firms; and (ii) the estimates of the success probabilities of the different projects.

The process is repeated for the number of periods set by the modeler. As time goes by, the program shows the changes in firms' profiles and the changes in the number of successful projects.

\section{Strategy}

In the simulation literature, models are exploited in different ways, depending on the type of experiments designed by the modeler. There are three main approaches:

1) The discovery of behavior. In this approach the model is used to observe a small set of trajectories, aiming to identify their main behavioral characteristics. The basic idea is that simple models often present complicated behavior that is difficult to anticipate from the models' structure. A close scrutiny of behavior is therefore key for the analysis. This is a complicated approach because trajectories are functions, not values, which means that the observed effects are functional behaviors, which 
are not easy to detect with present-day observation techniques ${ }^{7}$. This approach has been promoted and used mainly by the Santa Fe group (Gilbert 2008).

2) The response surface approach. This is a classical approach that does not focus on trajectories, but rather on certain parameters of the results. A steady state is typically assumed to exist, and to closely represent the state of affairs. This approach is widely used (see, for instance, Wagner (1995)) because it is simple to implement. It is just a matter of running several (hundreds of) scenarios and using appropriate statistical techniques to build a response surface for the desired parameters. No emergent behavior can be discovered with this approach, which is plagued with technical problems (lack of smoothness of the response function, presence of catastrophic behavior, and even difficulties with statistical techniques).

3) The analysis of purposeful behavior. This approach is a combination of the previous two. It allows the modeler to carry out multi-parameter simulation and introduce properties of the trajectories in the model (by means of some sort of "optimization," so that a large number of non-optimal states can be quickly discarded). Once an optimal behavior has been identified, by analyzing its neighborhood one can concentrate on the properties of the optimal trajectory. This is "Simulation Optimization" (Gosavi 2010).

Approaches 2 and 3 implicitly assume that a good grasp of the model's plausible behavior is at hand, which not true in our case, even after having conducted a theoretical analysis of it. ${ }^{8}$ In this work, therefore, we have taken the first approach.

\section{Baseline parameters}

In the analysis of the model that follows, we concentrate on two parameters: the "degree of sacrifice" (represented by $\alpha$ ) and the "threshold" (represented by T).

The sacrifice $\alpha$ represents the importance that managers attach to the long run. As already mentioned, it gives an indication of how willing managers are to forego immediate results in order to develop capabilities for the future.

The threshold $\mathrm{T}$ represents the satisficing level related with bounded rationality. It, too, is a number between 0 and 1 . The larger the value of $\mathrm{T}$, the more demanding managers will be in terms of project selection. If $\mathrm{T}=0$, managers will choose the first project they come across; if $\mathrm{T}=1$, managers will optimize by evaluating all projects and choosing the best one.

As both parameters lie between 0 and 1 , we explore the effects of different pairs of values $(\alpha, T)$ on the unit square. We start with an initial population of $N=1,000$ companies, which interact for at least 300 periods. We assume that all projects take one period to be completed, that they have the same economic value, and that they require the same investment. As a consequence,

\footnotetext{
7 Sometimes the only way to understand the roots of the system's behavior is by tracing it, following the computer program step by step. We often had to resort to this technique. In a sense this is a rather new approach to the analysis of simulation experiments, one not normally found in the literature.

${ }^{8}$ Experience with our type of model is small, and so far we have only a few pointers on how the model may evolve as a function of its structure. In this sense we are still trying to obtain some solid knowledge of its evolution. The exploration (simulation) phase is technically challenging, but a necessary step before additional theoretical refinements can be included in the model.
} 
the number of successful projects in a simulation round is a measure of the aggregate economic value generated by the firms.

We observe the evolution of the economy by looking at the distribution of company profiles. Note that there are seven meaningful types of firms, namely, $(0,0,1),(0,1,0),(1,0,0),(0,1,1)$, $(1,1,0),(1,0,1)$, and $(1,1,1)$. Profile $(0,0,0)$ is not meaningful for obvious reasons, as it would imply a firm with no capabilities at all. It could be included for completeness, but its interpretation would be awkward. At each time step we keep track of the proportion of companies (out of the 1,000) with each profile, and we plot the corresponding trajectories.

At the end of each round, the distribution of company profiles is an indicator of the economy's capacity to successfully tackle more challenging projects in the future. As companies with a $(1,1,1)$ profile have the highest capacity to successfully undertake future projects, the reference point in measuring an economy's potential is typically the proportion of type $(1,1,1)$ companies.

For simplicity we make the following additional assumptions in the analysis reported below ${ }^{9}$ :

1) The initial distribution of firms is uniform.

2) All management teams have the same preferences regarding the type of profile they would like to have in the future.

3) All management teams have the same prior probability distributions, representing the same initial perception about the true profile of their own firms.

Firm profiles change from period to period according to the transition probabilities $\lambda_{\mathrm{E}}, \lambda_{\mathrm{A}}, \lambda_{\mathrm{U}}$, and $\mu_{\mathrm{E}}, \mu_{\mathrm{A}}, \mu_{\mathrm{U}}$, introduced in the previous section. We assume that these probabilities are the same for all companies (they are set by the market "environment"). In what we report below, we use the following values for the transition probabilities:

$$
\begin{aligned}
& \lambda_{\mathrm{U}}=0.3, \lambda_{\mathrm{A}}=0.2, \lambda_{\mathrm{E}}=0.1 ; \\
& \mu_{\mathrm{U}}=0.7, \mu_{\mathrm{A}}=0.8, \mu_{\mathrm{E}}=0.9 .
\end{aligned}
$$

\section{Types of behavior}

In general the model is monotonous in the sense that $(1,1,1)$ dominates all other states. Therefore, it seems that all companies should have trajectories that attain $(1,1,1)$ as fast as possible and stay there forever. Somewhat surprisingly, this is not quite true.

By running multiple simulations for different values of $\alpha$ and $\mathrm{T}$, we have identified three main types of behavior, which we call selective, diffusive and catastrophic.

\footnotetext{
${ }^{9}$ These assumptions can be easily changed in the model implementation, and we plan to do so in the future.
} 


\subsection{Selective Behavior}

This type of behavior is the behavior to be expected given monotonicity. It is characterized by profiles "disappearing", one by one, from the total population, until a profile emerges as the "winner." ${ }^{10}$ The typical winner is profile $(1,1,1)$, meaning that all companies become excellent. An example of this behavior can be found in Figure 5, obtained for $\alpha=0.1, T=0.9$.

These parameter values mean, first, that firms are not willing to forego immediate results (with $\alpha=0.1$, managers evaluate projects by taking into account mainly the projects' immediate financial performance). At the same time, firms are rather demanding as to the kind of projects they choose (with $T=0.9$, they pick projects in an almost optimizing way). As can be seen in Figure 5(a), the population of firms is quickly dominated by the $(1,1,1)$ profile and remains dominated by it. In part (b) of the same figure we show the evolution of performance, measured by the number of successful projects. The proportion of successful projects gets to $100 \%$ because $(1,1,1)$ firms can undertake any type of project successfully. We say that $(1,1,1)$ companies are selected from the population, hence the name given to this type of behavior.

Selective behavior is a type of "Darwinian behavior," in which the fittest profile, namely $(1,1,1)$, sweeps all others away. An additional characteristic of these trajectories is their low levels of randomness (the variance at each point of time).

Not surprisingly, by swapping the values of $\alpha$ and T we obtain the same type of behavior (see Figure 6 , where $\alpha=0.9$ and $T=0.1$ ). In this case, firms do not optimize much in terms of project selection, but they are quite willing to forego short-term performance in exchange for future potential. If we plot all possible combinations $(\alpha, T)$ in a unit square, we can see that points above the downward sloping diagonal have selective behavior ${ }^{11}$ (see Figure 11).

\section{Figure 5}

Selective behavior $(\alpha=0.1, T=0.9)$.

(a) Evolution of company types (in \%).

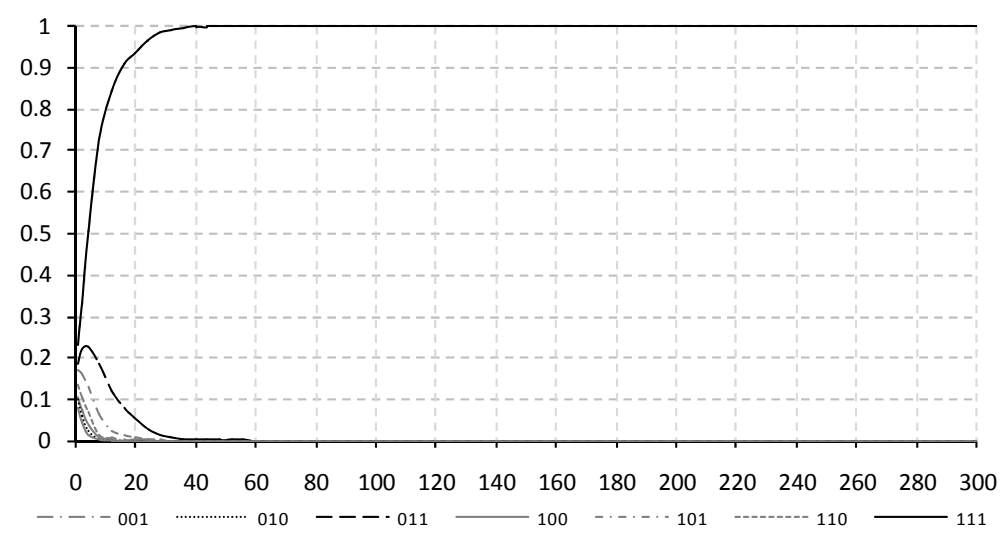

(b) Evolution of economic performance (number of successful projects).

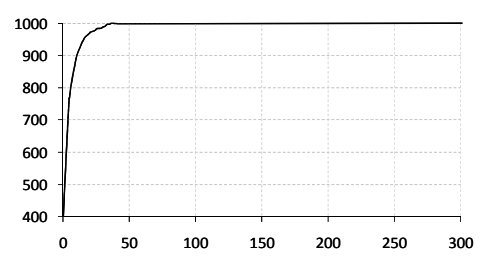

${ }^{10}$ When we say that a company profile "disappears", we mean that companies with that particular profile evolve (they acquire or lose capabilities) in such a way that, after a number of periods, there are no companies left with that profile among the total population of 1,000 firms.

${ }^{11}$ So far this is not a formal proof, just an observed result in our experiments. 


\section{Figure 6}

Selective behavior $(\alpha=0.9, T=0.1)$.

(a) Evolution of company types (in \%).

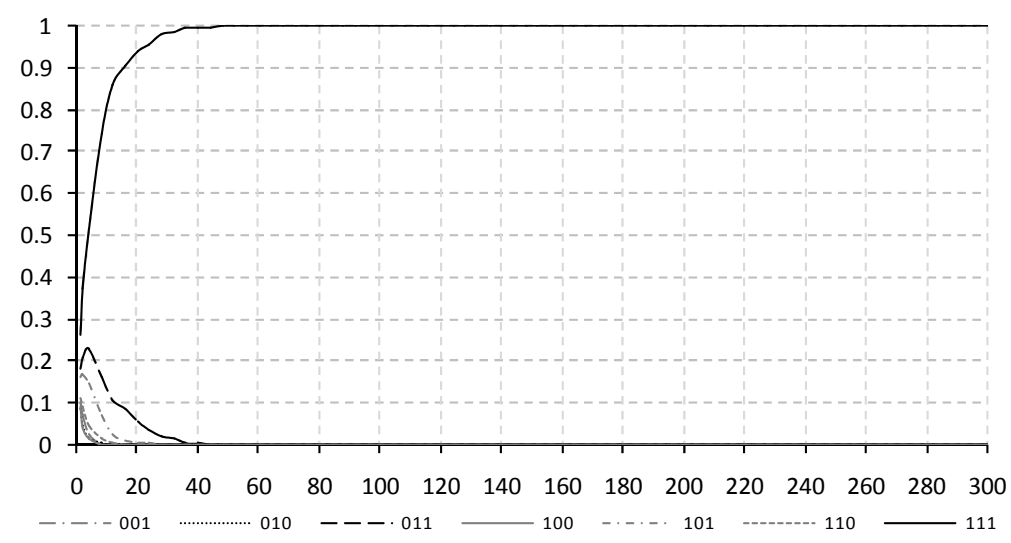

(b) Evolution of economic performance (number of successful projects).

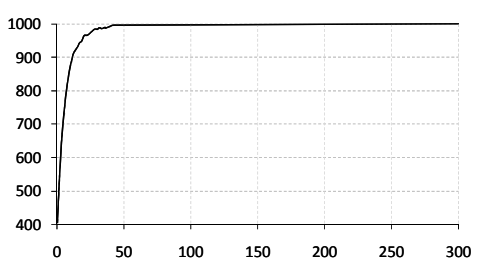

By observing the decisions that managers make at each iteration, we can, in fact, see the strong dominating properties of the $(1,1,1)$ profile, which quickly starts creating a cluster of companies of the same type.

\subsection{Diffusive Behavior}

In diffusive behavior the proportions of each company type stabilize after an initial transient period. As can be seen in Figure 7, no profile disappears. Diffusive behavior emerges when the degree of sacrifice $(\alpha)$ and the threshold $(\mathrm{T})$ are below the downward sloping diagonal of the unit square (Figure 11). In the particular case of Figure 7 , firms of type $(0,0,1)$ (firms with only efficiency and lacking the other two capabilities) end up being around 40\% of the population. Firms of type $(0,1,0)$ end at 25\% of the total. The proportion of firms in each profile fluctuates in the long run, never reaching a steady state, an effect that seems to be due to the learning process. In general, these trajectories look like sample paths of diffusion processes, hence the name.

\section{Figure 7}

Diffusive behavior $(\alpha=0, T=0)$.

(a) Evolution of company types (in \%).

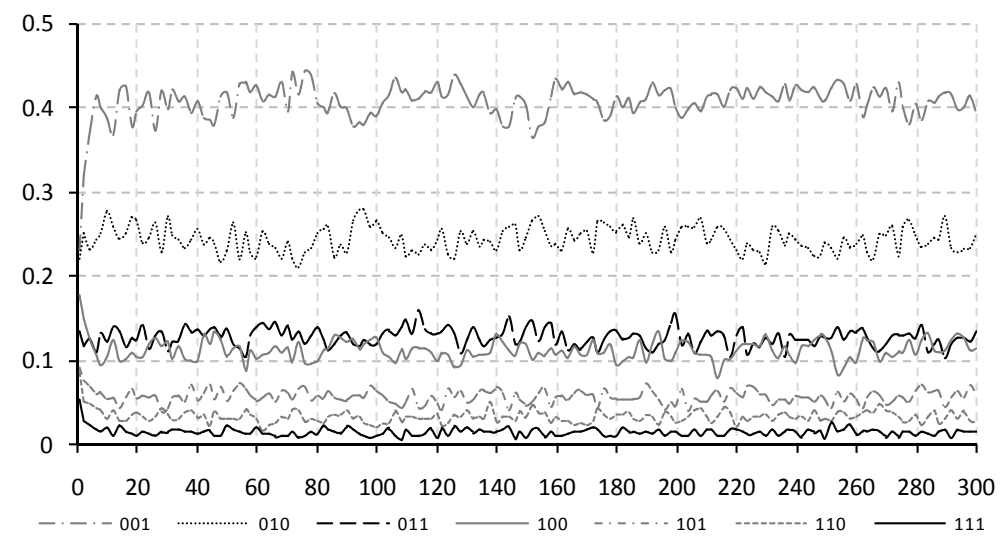

(b) Evolution of economic performance (number of successful projects).

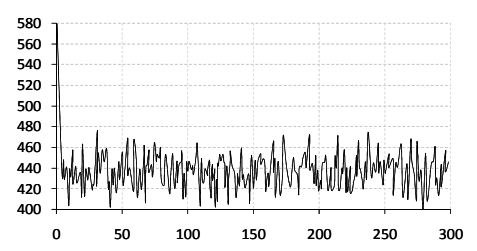


As time increases, profiles coexist in regular (and roughly cyclical) proportions. A limiting distribution for profile types does not exist in a simple sense. ${ }^{12}$ No complete extinction takes place, all profiles coexisting in roughly constant proportions. In graph (b) we see that about $43 \%$ of the projects are successful.

Figure 7 represents an extreme case because $\mathrm{T}=0$ means that managers accept the first project they come across (i.e., they choose projects randomly), and $\alpha=0$ means that managers are completely unwilling to forego immediate results in order to develop better firms for the future. With these values of $(\alpha, T)$, the model translates into a Markov Decision Problem (Sobel 1993), which can be solved analytically. We have solved it, with results in close agreement with the simulation. Note that companies with a $(1,1,1)$ profile represent only $1 \%$ of the population.

If the value of $\mathrm{T}$ increases while keeping $\alpha$ constant, a sort of selective behavior appears during the first periods, before settling into a diffusive pattern (see Figure 8 below). In this figure, the proportion of $(1,1,1)$ companies increases to $72 \%$ during the initial periods and then declines, showing the typical pattern of diffusive behavior in the long run. As the value of $\mathrm{T}$ gets closer to 1 , the drop in the proportion of $(1,1,1)$ companies takes longer to happen.

\section{Figure 8}

Diffusive behavior $(\alpha=0.5, \mathrm{~T}=0.43)$.

\section{(a) Evolution of company types (in \%).}

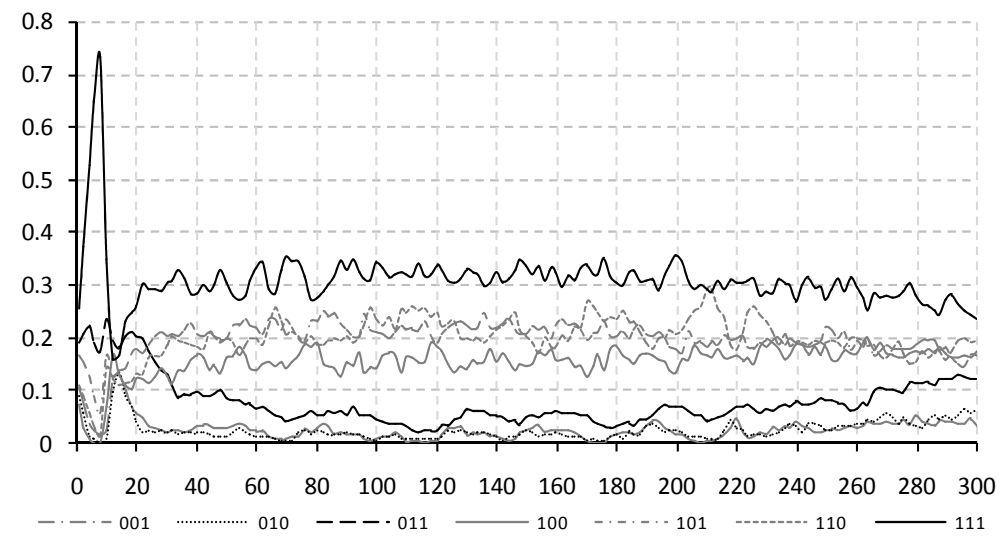

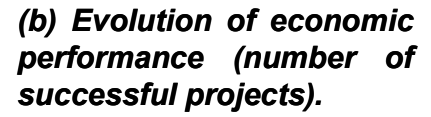

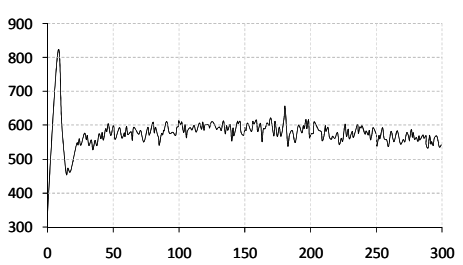

\subsection{Catastrophic Behavior}

Figure 8 hints at a third type of behavior that is more interesting than the previous ones. We call it catastrophic because it is represented by sudden drops in the proportions of certain company types, as in Figure $9(\alpha=0,72 ; T=0,275)$. This behavior occurs for a range of parameters clustered in a seemingly irregular band around the downward sloping diagonal of the unit square, $\alpha+\mathrm{T}=1$.

\footnotetext{
${ }^{12}$ It does exist in more sophisticated approaches, in which paths may be averaged over time. When the averaging option of the program is active, the paths follow smooth patterns that do converge to a steady state.
} 


\section{Figure 9}

Catastrophic behavior $(\alpha=0.72, \mathrm{~T}=0.275)$.

(a) Evolution of company types (in \%).

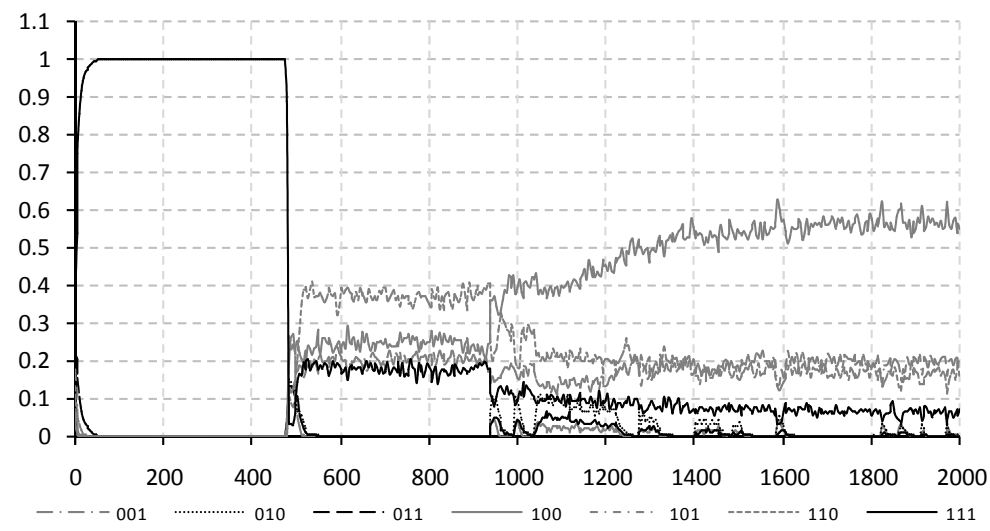

(b) Evolution of economic performance (number of successful projects).

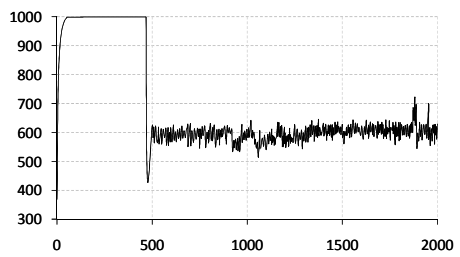

During a long initial phase, all companies become $(1,1,1)$ and performance is optimal, with $100 \%$ of successful projects. After that, the proportion of $(1,1,1)$ companies suddenly falls to almost 20\%, and remains there for another long phase, after which the behavior turns into a diffusive pattern, with a majority of type $(1,0,0)$ companies. The overall performance after the sudden drop falls to approximately $60 \%$ (part (b) of the figure)

Analogous behaviors result from different combinations of values $(\alpha, T)$. When we increase the value of $\mathrm{T}$ for a given value of $\alpha$, the general behavior is roughly the same (although the shapes of the trajectories are different). This phenomenon illustrates some interesting features, such as the importance of the transient periods that precede stability, as well as the appearance of catastrophic drastic changes in the composition of the firm population.

A simple, approximate explanation of this catastrophic behavior is as follows. First, in a world where all companies are $(1,1,1)$, project success gives managers little additional information, because if all companies are $(1,1,1)$, all projects will be successful with probability 1 . Mistakes may occur, however, when managers select projects under bounded rationality, which will result in negative learning. When $\mathrm{T}$ is small, for instance, project selection is more random, which may lead some managers to choose inferior projects. Once this happens, the imitation effect produced by a relatively high value of $\alpha$ sweeps through the entire population. The "ideal" world is over and one returns to a messy, diffusive behavior. This is a variety of the story in which a butterfly flapping its wings in Japan can cause a hurricane in California. These arguments can be made rigorous in the mathematical sense, and we have done so under strong restrictions. $^{13}$

\footnotetext{
${ }^{13}$ A fully rigorous mathematical analysis is still under way, although the nature of the problem seems to make it intractable. In any case, a detailed mathematical analysis falls well beyond the scope of this paper, which is centered on exploiting the model's emergent behavior properties by means of experimental techniques.
} 


\section{Figure 10}

Catastrophic behavior $(\alpha=0.61, T=0.385)$.

(a) Evolution of company types (in \%).

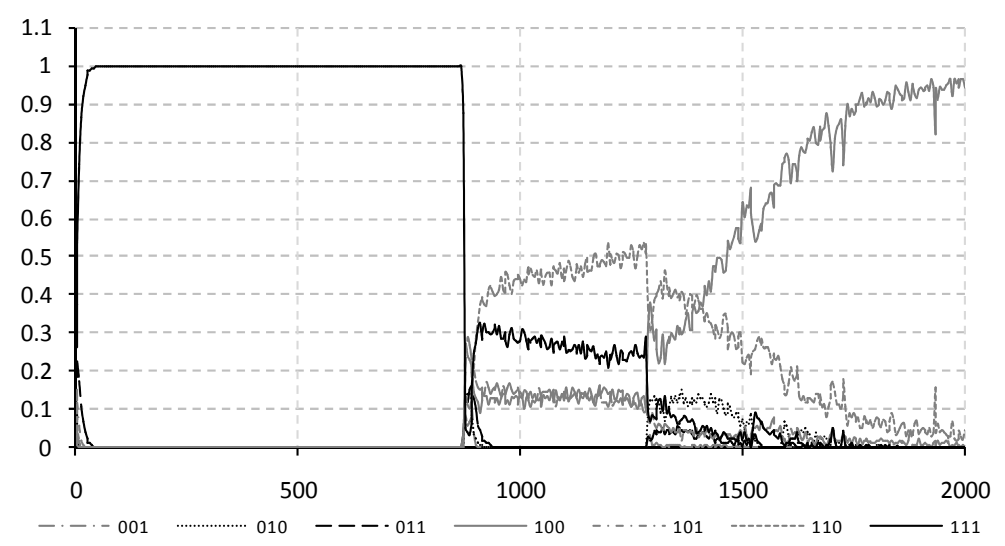

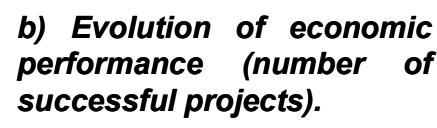

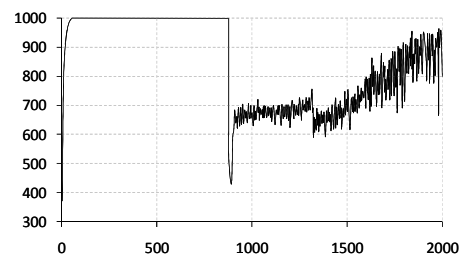

Just to further illustrate this outcome, Figure 10 depicts another situation with a different transient evolution. As one can see in the upper part of the graph, the proportion of $(1,1,1)$ companies goes up to $100 \%$ and remains there for a long period. A first catastrophe occurs around period 900, and a second one around period 1300. The first catastrophe almost eliminates all $(1,1,1)$ firms, while the second one cuts down the number of $(1,1,0)$ firms. The causes of such behavior are not straightforward.

The results of the simulation experiments are summarized in Figure 11 below, which shows the tessellation of the unit square. The combinations of $\alpha$ and $\mathrm{T}$ are roughly divided into two triangles, labeled with the dominant behavior that is displayed in each one. The two triangles are separated by a thin set of catastrophic behavior, marking the transition from the diffusive to the selective areas. The selective area is more homogeneous that the diffusive one. In almost all the experiments performed, moving around the selective area results in behaviors that look alike.

\section{Figure 11}

The tessellation of the $(\alpha, T)$ unit square

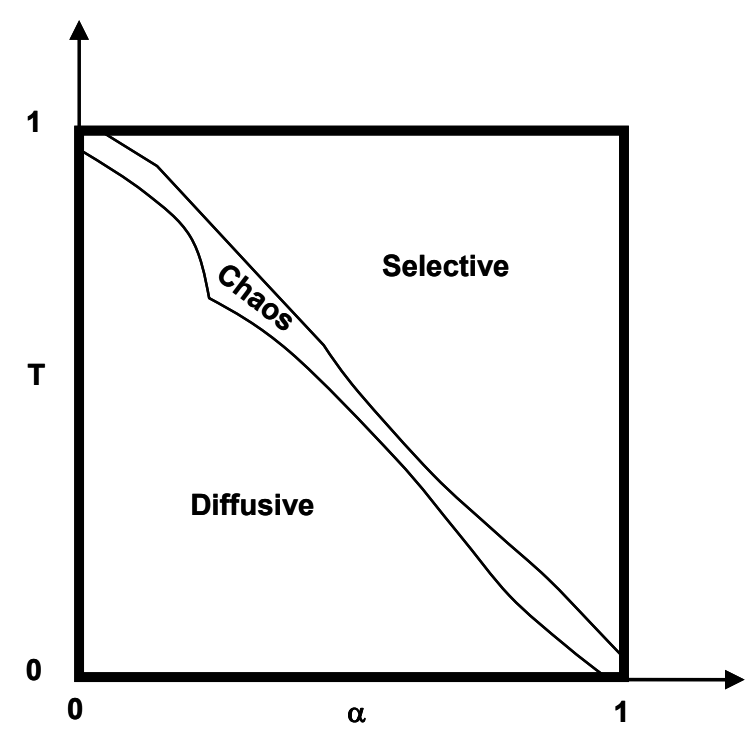




\section{Managerial implications}

Below we summarize several insights that emerge from our work with the model.

1) First of all, in a complex situation, intuition cannot predict the evolution of a single company. Quick estimates based on a general (qualitative) appraisal of capabilities may lead to the wrong conclusion. In real life, the probability of surviving a catastrophe such as those produced in the model is near zero. Therefore, after a chaotic period many companies will not survive. And, surprisingly, the crisis could be caused by logical changes in the mental attitudes of managers.

2) Performance seems to be very sensitive to managers' estimates about the true profile of their own company. Even companies with a $(1,1,1)$ profile can be very unstable if their management has a distorted knowledge of their profile. This sounds like common sense, but the model offers an additional insight. Initially, the manager has a prior on the company's profile; unless this prior is concentrated around the true profile, the prior distribution will give weight to other profiles. Because managers make their decisions based on expectations, an erroneous prior (which could be due to fluctuations in learning) may lead managers to make wrong estimates about the expected value of the available projects and, therefore, to choose projects that are only second-best (or worse). This would give a positive probability of losing capabilities. Once lost, capabilities are difficult to recover, thus reducing the probability of the $(1,1,1)$ state. When managers consider only (E)ffectiveness, ignoring (A)ttractiveness and (U)nity, things get worse. From all this we conclude that stability is highly dependent on managers' ability to estimate the true profile of their companies. The old Greek aphorism "Know Thyself" is crucial for success, but it has a consequence that is not at all trivial: if you seek only efficiency, your future looks bleak.

3) The recipe for an economy's (or company's) success is to keep both $\alpha$ and T large. Companies that are willing to accept sacrifices in the short run in order to increase future potential (high $\alpha$ ) and, at the same time, try to follow a more rational decision-making process (high $\mathrm{T}$ ) appear to be more stable than others. The attitude of such companies makes them more likely to succeed in more projects. This is a golden rule, which requires a certain lack of short-term greed and a degree of trust within the company structure.

4) In addition, the analysis provides clues on how to change attitudes. Imagine a company that changes its managing team because it wants to evolve from a greedy, profit-oriented firm to a future-oriented one, i.e., from the Diffusive zone to the Selective zone. Our analysis recommends doing this as fast as possible because "crossing the diagonal" is dangerous and should be done quickly. Managers should be prepared to see peculiar behavior that could discourage the attempted change and push them back into the Diffusive zone. Once in the Selective zone, the company still has a substantial probability of failing; but long run profitability requires that they cross over. Companies could thus be trapped in a paradox that is difficult to solve. 
5) Being persistent in choosing $(1,1,1)$ projects seems a good idea, even if the projects' success probability is not that high or the cost of choosing them is large. Type $(1,1,1)$ projects help managers develop their employees, giving the company the opportunity to develop a $(1,1,1)$ profile. If this situation is reached, the company can undertake a greater number of challenging projects and so can remain optimal. Suppose that, at a given stage, type $(1,1,1)$ companies abound and that a given firm, by an "imitation effect," would like to imitate the leaders. What happens if that company is not $(1,1,1)$ ? By the imitation effect, it will tend to select $(1,1,1)$ projects and will therefore experience failures. If after a few mistakes managers become "demoralized" and think that $(1,1,1)$ projects are too complex for their company, they will never achieve excellence. Thus, unless managers have an accurate knowledge of their company's profile, a blind tendency to "follow the leader" brings with it the risk of overreaching.

\section{Limitations and further work}

We have presented a model that simulates the aggregate behavior of a population of firms resulting from specific management decisions. The model features a learning process that produces changes in companies' capabilities. Decisions are made under bounded rationality (satisficing behavior), and managers can sacrifice short-term performance in exchange for qualitative variables that affect their firms' future potential. The model provides a structured setting in which these issues can be rigorously analyzed.

Another relevant feature of our approach is that it illustrates how a complicated process of enterprise evolution based on managers' attitudes and values can be modeled. A fairly simple and parsimonious description of reality leads to emergent behaviors that provide scope for the analysis of feedback phenomena involving learning.

We believe that the model includes the minimum number of features necessary to characterize learning enterprises. We have tried to simplify the model by removing some of the features, but this quickly brings it into well known, simple behavior. The model shows that features like learning, bounded rationality, concern for others' welfare, uncertainty, and so on, can be modeled and analyzed simultaneously. No harm arises from this, and the explanatory power of the model increases noticeably. All this is at the price of relying on simulation for the analysis, which to some extent decreases understanding of the deep relationships in the system. Even so, we believe it is important to shed light on transient behaviors.

Bounded rationality plays an important role in the results obtained. Without it, the optimal behavior would quickly converge to $(1,1,1)$ profiles, which would consistently dominate the others. Although the model has proved useful for exploring a series of relevant phenomena, it also has a number of limitations that are worth pointing out.

1) One difficulty stems from the fact that, in the model's current form, it is not easy to anticipate the behavior that will result from specific parameter values, other than in terms of the approximate tessellation shown in Fig. 11. The only safe way to learn about behavior is by running the model and observing the outcome. There is work to be done in order to explain behavior as the logical consequence of the processes underlying the model dynamics. 
2) It is difficult to interpret the meaning of specific parameter values (what is the meaning, for example, of an increase in the threshold from $T=0.2$ to 0.4 ?) In its current form, the model essentially performs "qualitative simulation" (Kuipers 1994), which may provide qualitative insights into the consequences of learning, decision making, etc. but not clear, measurable results.

Regarding future research there are at least five main areas for further work.

1) Understanding better the effects of changes in the parameters that define the environment: transition probabilities, characteristics of the pool of projects, probabilities of project success, initial distribution of firms' profiles, managers' preferences, and different prior distributions.

2) Explore the effect of heterogeneous groups of firms (until now we have only studied the evolution of homogeneous groups) by allowing firms with a given number of failures to go bankrupt and disappear; and exploring different implementations of bounded rationality (for example, by using "bounded evaluation capability").

3) Explore the "unavoidable" character of learning. With the present formulation of the model and due to bounded rationality, any firm may learn as a consequence of undertaking projects that do not exactly match their profile. There could be firms, however, that decide not to learn (and to collect short-term economic results). Although these could find appropriate projects, this is an option that the model does not currently consider.

4) Allow more than one "economy" in an "international" setting, and explore the results of different management decisions. For example, "more advanced" economies could generate more and more demanding projects that firms in other economies would not be able to undertake with the same probability of success, thus unveiling a need for change in management practices in underperforming economies.

5) Investigate a more advanced characterization of the difference between capability types, as suggested in Appendix 1. The idea is to compute the probabilistic hierarchy out of the dynamic evolution of (U)nity, (A)ttractivenes and (E)ffectiveness suggested by motivation and other human resources theories. 


\section{Appendix 1}

Capabilities names and transition probabilities

As indicated in Section 2, in our model the capabilities that define a firm's profile are called Effectiveness (E), Attractiveness (A), and Unity (U). The reason for choosing these names is that we plan to continue working on a more elaborate capability scheme, which will describe the capability development process better, giving the capabilities a much more specific meaning and thus depicting a richer development process, closer to the actual learning dynamics in organizations.

Our plan is to work with the following specific capabilities: Effectiveness (E), defined as the degree to which a company is able to achieve measurable (typically financial) results; Attractiveness (A), or the degree to which employees develop professionally and enjoy their jobs; and Unity (U), or the degree to which employees identify with the organization's goals and values, as well as with other members of the organization (see Pérez López (1993) and Rosanas (2008)).

To give some indication of what we have in mind for the future, suffice it to say that we conceive of these capabilities as originating in the different types of motivation a person may have. The distinction between "intrinsic" and "extrinsic" motives comes from the literature of the '50s and '60s (see, e.g., Saleh and Hyde (1969) and Lawler (1969)). Ryan and Deci (2000) and Lindenberg (2001) distinguish between "intrinsic motivation, which refers to doing something because it is inherently interesting or enjoyable, and extrinsic motivation, which refers to doing something because it leads to a separable outcome." Frey (1998), Osterloh and Frey (2003) and Gottschalg and Zollo (2007) consider that intrinsic motivation may have a hedonic component of "enjoyment", while at the same time there is a normative intrinsic motivation out of a sense of "obligation".

Our approach will parallel the above distinctions, with the additional notion that obligation may also be enjoyable (this is the case, for example, when we do something we dislike in itself, not because it is an obligation but rather because we are happy to satisfy someone else's needs). This is what Perez López (1993) and Rosanas (2008) call "transcendent" motives.

Simon (1997) notes that the constituency that predominantly has a direct interest in the firm's objectives are the firm's customers, whereas employees are directly interested in the rewards offered by the firm (both tangible and intangible, extrinsic and intrinsic). For employees to really pursue the firm's objectives, they must identify with them (Simon 1997). What we call unity (identification of the organization's members with the organization's objectives) is essential for the firm's survival in the future and is based on transcendent motives.

The three capabilities are interrelated. For instance, attractiveness plays an important role in obtaining the desired output, although sometimes it may shift attention to the satisfaction of employees' needs, rather than customers' needs. At the same time, effectiveness will be important in satisfying extrinsic motives. Several authors have recently touched upon some of these aspects from different perspectives. Giancola (2001) discusses issues close to the notion of attractiveness. The arguments of Shuck and Wollard (2010), Choi and Wang (2009) and Hekman et al. (2009) are reminiscent of our concept of unity.

For the purposes of this paper, though, we treat E, A, U capabilities in a much simpler way, though consistent with the meanings stated above. Changes in firm profile (i.e., changes in a firm's capabilities) are modeled in a probabilistic way, which in terms of the model parameters is described in Figure 3. In order to make the corresponding probabilities consistent with the assumptions discussed above, we set the following constraints on probabilities $\lambda$ and $\tilde{\mu}$ 


\section{Appendix 1 (Continued)}

\section{Table A1.1}

Constraints on probabilities $\lambda$ and $\tilde{\mu}$

$$
\begin{array}{ll}
\lambda_{\mathrm{U}} & <\mu_{\mathrm{U}} \\
\lambda_{\mathrm{A}} & <\mu_{\mathrm{A}} \\
\lambda_{\mathrm{E}} & <\mu_{\mathrm{E}}
\end{array}
$$

The columns indicate that acquiring (U)nity is harder (less likely) than acquiring (A)ttractiveness, which in turn is harder than acquiring (E)ffectiveness. Also, (U)nity can be more easily lost than (A)ttractiveness, which in turn is more likely to be lost than (E)ffectiveness. Horizontally, the table reads that we assume it to be harder to acquire a capability ("learning") than to lose one ("unlearning”). 


\section{Appendix 2}

Formal model structure

We use the letter $\mathrm{x}$ to designate a generic firm, $\mathrm{x}=\left(\mathrm{x}_{1}, \mathrm{x}_{2}, \mathrm{x}_{3}\right)$, with the three basic capabilities ( $\mathrm{x}_{1}$ represents unity, $\mathrm{x}_{2}$ represents attractiveness, and $\mathrm{x}_{3}$ represents effectiveness).The "state of the economy" can then be described by the number of companies of each type.

Projects are also characterized in terms of unity, attractiveness, and effectiveness, and are represented by $\mathrm{y}=\left(\mathrm{y}_{1}, \mathrm{y}_{2}, \mathrm{y}_{3}\right)$.

Each management team has preferences regarding the type of company they would like to have in the future. These preferences are described by

$$
\bar{\gamma}=\left(\bar{\gamma}_{1}, \bar{\gamma}_{2}, \bar{\gamma}_{3}, \bar{\gamma}_{4}, \bar{\gamma}_{5}, \bar{\gamma}_{6}, \bar{\gamma}_{7}\right)
$$

where each component represents the relative importance that managers assign to each of the seven company types. The values of these parameters remain fixed throughout successive rounds.

Managers have uncertainty regarding:

1) The company's actual profile;

2) Whether a certain project will succeed if undertaken by a given firm;

3) A project's potential to develop a particular capability if a given firm were to undertake that project.

We assume that managers allocate their time, resources, and efforts in such a way that the results satisfice (but do not necessarily maximize) managers' goals, and that managers are willing to forego short-term results in exchange for learning and future potential. While the target profile remains fixed throughout the simulations, the knowledge mentioned in (i) and (ii) above may evolve through time, so that companies and managers can and do learn $\bar{\gamma}$. Managers learn about their own company type, but they also learn about the success probability of each type of project.

The process by which managers select projects depends on three elements: the type of company they would like to be in the future; the (incomplete) knowledge they have about the company's profile, which is updated along the way; and the (incomplete) knowledge they have about the success probability of a project, which also is updated along the way.

\section{Updating managers' knowledge about their own company's profile}

A key element of the model is the way in which managers form their beliefs about the profile of their own company. Because managers do not know the true profile, they have a prior probability distribution $\pi$ defined as follows:

$$
\pi(x)=\pi\left(x_{1}, x_{2}, x_{3}\right)=P\left(\text { true profile of the company is }\left(x_{1}, x_{2}, x_{3}\right)\right)
$$




\section{Appendix 2 (Continued)}

We assume that the initial distribution is uniform over all possible profiles, which is a noninformative prior distribution. This is a reasonable assumption in decision making under uncertainty (and is easily modified at a later stage). As new information becomes available, the probability distribution is updated in a Bayesian way.

\section{Probability of succeeding when a given project is undertaken by a firm}

Another important element is the way in which managers form their beliefs about the possibility of success if they undertake a particular project. Denote by $\mathrm{P}_{\mathrm{T}}(\mathrm{x}, \mathrm{y})$ the "true" probability of success, defined for all pairs $(\mathrm{x}, \mathrm{y})$ as:

$$
P_{T}(x, y)=P(\text { success } \mid \text { company }=x \text {, project }=y) \text {. }
$$

The subjective perception that managers have of (2) will be denoted by $\mathrm{P}_{\mathrm{S}}(\mathrm{x}, \mathrm{y})$. Note that while managers make their decisions based on $\mathrm{P}_{\mathrm{S}}$, the actual frequency of successes and failures in the simulations happen according to $\mathrm{P}_{\mathrm{T}}$. The process by which managers form their subjective perceptions is modeled by means of a neural network. In particular, the market makes public all quadruples

\{Initial firm profile; Project type; Success or failure; Final firm profile\}

generated during each simulation round. Based on this information, managers update their knowledge. For simplicity we assume that the learning process is the same for all companies in the sense that it is the same type of neural network that processes the information in all firms. We thus deal with three probability measures:

1) $\mathrm{P}_{\mathrm{T}}(\mathrm{x}, \mathrm{y})$, the "true" probability that a company with profile $\mathrm{x}$ succeeds when it undertakes a project with profile $y$. This probability is assumed to be a feature of the "environment," determined by the modeler.

2) $P_{S}(x, y)$, the subjective estimate that a company of type $x$ will succeed if it undertakes a project of type y. This measure is updated as new information is generated by the environment in each round and should converge to $\mathrm{P}_{\mathrm{T}}(\mathrm{x}, \mathrm{y})$.

3) $P_{F}(x, y)$, a frequency. It tells us how often a project of type y has actually succeeded when undertaken by a company of profile $x$ during the different rounds. As time goes by, it should converge to $\mathrm{P}_{\mathrm{T}}(\mathrm{x}, \mathrm{y})$.

\section{Evolution of firm profiles}

Another characteristic of the model is the fact that, after working on a project, a company may develop a desired attribute or it may lose it (because its choice of project was excessively shortsighted or simply inappropriate). 


\section{Appendix 2 (Continued)}

The modification of profiles is modeled by a transition matrix that specifies with what probability a company evolves from one profile to another (in one period) as a consequence of undertaking a particular project. Consider a company with profile $\mathrm{x}=\left(\mathrm{x}_{1}, \mathrm{x}_{2}, \mathrm{x}_{3}\right)$ that undertakes project $\mathrm{y}=\left(\mathrm{y}_{1}, \mathrm{y}_{2}, \mathrm{y}_{3}\right)$. The profile at the end of the round will be denoted by $\mathrm{x}^{+}=\left(\mathrm{x}_{1}^{+}, \mathrm{x}_{2}^{+}, \mathrm{x}_{3}^{+}\right)$:

$$
\left(x_{1}, x_{2}, x_{3}\right) \stackrel{\left(y_{1}, y_{2}, y_{3}\right)}{\longrightarrow}\left(x_{1}^{+}, x_{2}^{+}, x_{3}^{+}\right)
$$

The new profile is modeled by drawing from the probability distribution

$$
P\left[x^{+}=\left(x_{1}^{+}, x_{2}^{+}, x_{3}^{+}\right) \mid x=\left(x_{1}, x_{2}, x_{3}\right), y=\left(y_{1}, y_{2}, y_{3}\right)\right],
$$

where we explicitly assume that the new value of each attribute is independent of the new value of the other attributes. The probability that after one round $\mathrm{x}_{1}{ }^{+}=1$ (that is, that after having worked on a project, the company has acquired unity) will be denoted by $\mathrm{g}_{1}\left(\mathrm{x}_{1}, \mathrm{y}_{1}\right)$. In an analogous way, $\mathrm{g}_{2}\left(\mathrm{x}_{2}, \mathrm{y}_{2}\right)$ and $\mathrm{g}_{3}\left(\mathrm{x}_{3}, \mathrm{y}_{3}\right)$ will denote the probability that the company has acquired attractiveness $\left(\mathrm{x}_{2}{ }^{+}=1\right)$ and effectiveness $\left(\mathrm{x}_{3}{ }^{+}=1\right)$. In general,

$$
g_{i}\left(x_{i}, y_{i}\right)=P\left(x_{i}^{+}=1 \mid x_{i}, y_{i}\right)
$$

where $g_{i} \in[0,1]$. Given the independence of the attributes, if a company chooses to undertake project $\left(\mathrm{y}_{1}, \mathrm{y}_{2}, \mathrm{y}_{3}\right)$, each attribute of the company (each $\mathrm{x}_{\mathrm{i}}$ ) will evolve according to a controlled Markov chain (see Chung (1982), Taylor and Karlin (1998), or Heyman and Sobel (2003)) with transition matrix $\mathrm{A}_{\mathrm{i}}$ :

$$
A_{i}=\left[\begin{array}{ll}
P\left(x_{i}^{+}=0 \mid x_{i}=0, y_{i}\right) & P\left(x_{i}^{+}=1 \mid x_{i}=0, y_{i}\right) \\
P\left(x_{i}^{+}=0 \mid x_{i}=1, y_{i}\right) & P\left(x_{i}^{+}=1 \mid x_{i}=1, y_{i}\right)
\end{array}\right] .
$$

Using (3), this matrix can be written as

$$
A_{i}=\left[\begin{array}{cc}
1-g_{i}\left(0, y_{i}\right) & g_{i}\left(0, y_{i}\right) \\
1-g_{i}\left(1, y_{i}\right) & g_{i}\left(1, y_{i}\right)
\end{array}\right] .
$$

Note that it is the project that determines the matrix, and recall that the matrix is unknown to managers (i.e., its components are a feature of the environment, determined by the modeler).

In order to simplify notation, we let $\lambda_{i}$ denote the probability that a company lacking an attribute may acquire it after working on a project with that attribute. That is, for $I=1,2,3$,

$$
\lambda_{i}=g_{i}(0,1)=P\left(x_{i}^{+}=1 \mid x_{i}=0, y_{i}=1\right) .
$$

Likewise, we let $\mu_{\mathrm{i}}$ denote the probability that a company may lose an attribute after working on a project that does not have that attribute:

$$
\mu_{i}=1-g_{i}(1,0)=P\left(x_{i}^{+}=0 \mid x_{i}=1, y_{i}=0\right),
$$




\section{Appendix 2 (Continued)}

for $I=1,2$, 3. We impose the following conditions on these parameters:

1) Invariance, which means that a capability cannot change when both the company and the project have it, or both lack it. In other words, for $\mathrm{I}=1,2,3$,

$$
g_{i}(1,1)=P\left(x_{i}^{+}=1 \mid x_{i}=1, y_{i}=1\right)=1,
$$

and

$$
g_{i}(0,0)=P\left(x_{i}^{+}=1 \mid x_{i}=0, y_{i}=0\right)=0 .
$$

2) Entropy, which means that a weak project attribute is less determinant of the final result than a weak company attribute. That is, for $I=1,2,3$, we assume that

$$
g_{i}(0,1) \leq g_{i}(1,0)
$$

3) Difficulty, which has already been discussed in Appendix 1 (i.e., acquiring unity is harder than acquiring attractiveness, etc.). As we have seen in Table A1.1, we write:

$$
\lambda_{1} \leq \lambda_{2} \leq \lambda_{3} \text { and } \mu_{1} \geq \mu_{2} \geq \mu_{3} .
$$

\section{Decision Making}

Two criteria are used to choose projects and assign them to firms. One captures the idea that managers would like to choose the project that maximizes expected NPV. This, however, would require them to compute the success probability $\mathrm{P}_{\mathrm{T}}(\mathrm{x}, \mathrm{y})$, which is not observable. A solution would be to use the subjective perception $\mathrm{P}_{\mathrm{S}}(\mathrm{x}, \mathrm{y})$, but the problem is that managers do not know the true profile of their firm. We thus consider the following version of the Expected $\mathrm{NPV},{ }^{14}$

$$
V(y)=N P V(y) \cdot \sum_{\text {all } x} P_{S}(x, y) \cdot \pi(x)
$$

As we are assuming that the financial value of all projects is the same, we may assume NPV $(y)=1$ for all y, which yields

$$
V(y)=\sum_{\text {all } x} P_{S}(x, y) \cdot \pi(x)
$$

\footnotetext{
${ }^{14}$ Note that the summation has seven terms, for there are only seven company profiles.
} 


\section{Appendix 2 (Continued)}

The other criterion has to do with managers' aspirations (goals) regarding the type of company they would like to have in the future, thus modeling the idea that managers are also interested in projects that will bring their firm closer to their goal. We proceed in two steps. First, we take into account the wishes or desires of the management team, represented by $\bar{\gamma}$; second, such desires are tempered by the "imitation effect," which is the attraction that managers feel toward projects that successful companies chose in the past.

To start, note that

$$
\sum_{\substack{\text { all projects } y \\ \text { undertaken by } x}} P_{T}(x, y)
$$

is an estimate of the success of a company with profile $\mathrm{x}$. As $\mathrm{P}_{\mathrm{T}}(\mathrm{x}, \mathrm{y})$ is not observable and $\mathrm{P}_{\mathrm{S}}(\mathrm{x}, \mathrm{y})$ is different for each company, we use the frequency measure $\mathrm{P}_{\mathrm{F}}(\mathrm{x}, \mathrm{y})$. If one considers the expected net present value of a project to be a measure of success, since all projects are alike, the above expression is a proxy for the total value earned by a company in a given simulation round. In an analogous way,

$$
G(x)=\sum_{\begin{array}{c}
\text { all companies all projects } y \\
\text { of type } x \text { undertaken by } x
\end{array}} P_{F}(x, y)
$$

is a proxy for the total value earned by all companies of type $\mathrm{x}$. The function $\mathrm{G}$ is used to model the inclination to imitate other companies. Note that $\mathrm{G}(\mathrm{x})$ can be computed from the data generated by the system in each round.

Managers' preferences regarding future company profiles are given by (1), where the components $\bar{\gamma}_{x}$ represent the relative importance that the managers assign to each company type. These preferences, which remain fixed throughout successive rounds, should be combined with the fact that managers are not blind to what goes on in their environment (imitation effect, which goes beyond the concept of mimesis in neo-institutional theory (Di Maggio and Powell 1983)). How to combine the two variables is open to discussion, but in line with the tradition of System Dynamics (see, for example, Meadows (2008)), we adopt a multiplicative approach. We therefore define $\gamma_{x}=\bar{\gamma}_{x} \cdot G(x)$, so that

$$
\gamma=\left(\bar{\gamma}_{1} G(1), \bar{\gamma}_{2} G(2), \bar{\gamma}_{3} G(3), \bar{\gamma}_{4} G(4), \bar{\gamma}_{5} G(5), \bar{\gamma}_{6} G(6), \bar{\gamma}_{7} G(7)\right)
$$

The second criterion used by managers to choose projects is thus

$$
\begin{aligned}
W(y) & =\sum_{x^{+}} \gamma_{x^{+}} \cdot P\left(x^{+} \mid y\right) \\
& =\sum_{x^{+}} \gamma_{x^{+}}\left(\sum_{x} P\left(x^{+} \mid x, y\right) \cdot \pi(x)\right),
\end{aligned}
$$

where the probability is to be understood as an (observed) frequency. 


\section{Appendix 2 (Continued)}

We have developed two indices, V (y) and $\mathrm{W}(\mathrm{y})$, for each project y. It is easy to see that both indices take values in $[0,1]$. The first index is related to the project's efficiency (its capacity to generate short-term profits), while the second one captures how closely the project is aligned with managers' preferences regarding the future of the company. We combine the two indices as follows:

$$
D(y)=(1-\alpha) \cdot V(y)+\alpha \cdot W(y)
$$

where $\alpha$ is managers' willingness to sacrifice short term profits in exchange for a better company profile in the future. Obviously, $0 \leq \mathrm{D}(\mathrm{y}) \leq 1$.

In the process of project selection, managers do not maximize this index. Rather, they fix a threshold $\mathrm{T}$ and choose the first project for which $\mathrm{D}(\mathrm{y}) \geq \mathrm{T}$. $^{15}$

If $\alpha=1$ (complete willingness to sacrifice immediate profits), the decision criterion becomes $\mathrm{D}(\mathrm{y})=\mathrm{W}(\mathrm{y})$, meaning that the weight in the decision making process is carried by the managers' long-term vision of the type of company they would like to be in the future.

If $\alpha=0$, the decision index would be $\mathrm{D}(\mathrm{y})=\mathrm{V}(\mathrm{y})$, meaning that managers exclusively seek short-term profits. Figure A2.1 below shows a detailed diagram of the model consistent with the preceding discussion.

\section{Figure A2.1}

Detailed Model Structure

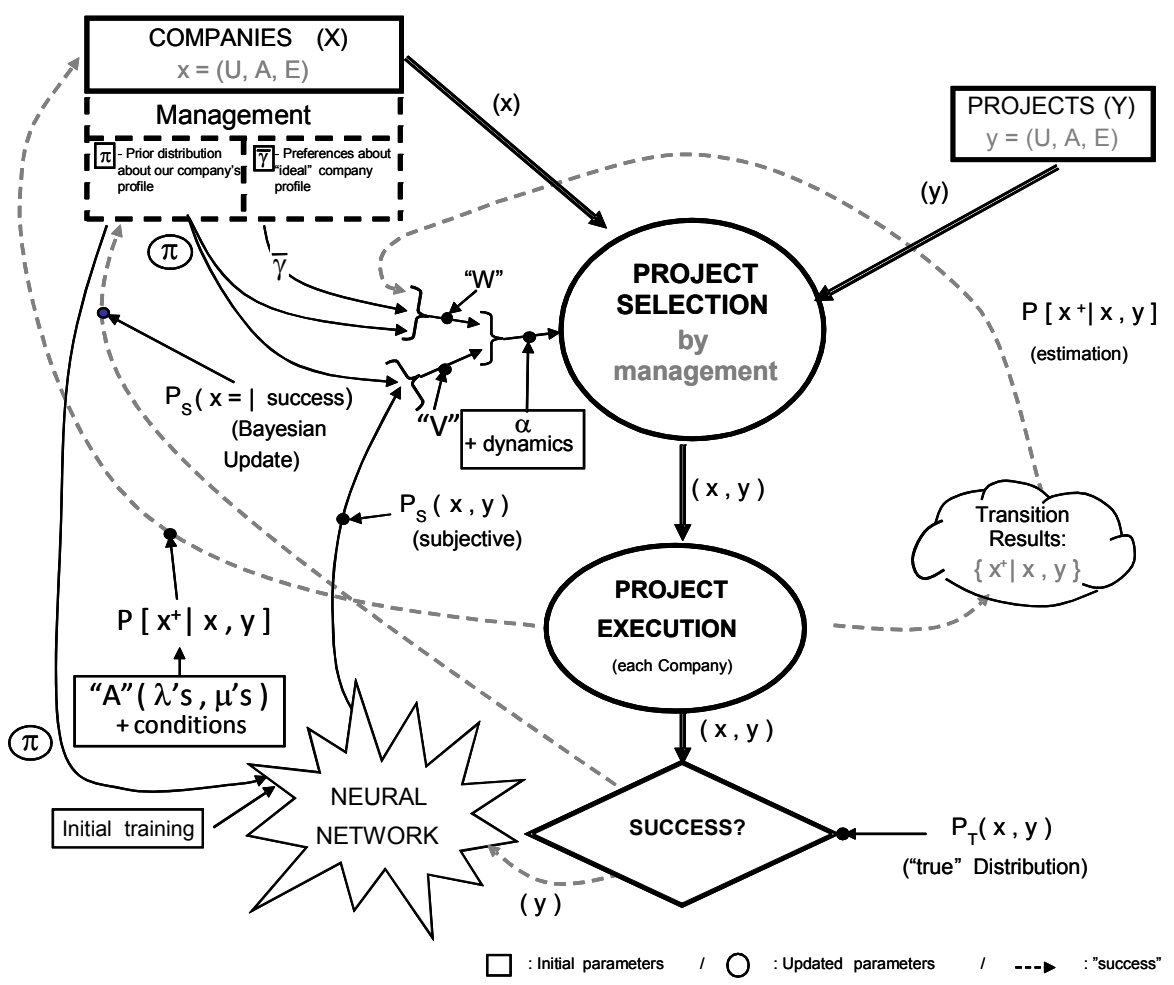

\footnotetext{
${ }^{15}$ Currently, projects of different types are successively "offered" to each company in a random order.
} 


\section{References}

Agarwal, R. and C. E. Helfat (2000), Strategic renewal of organizations, Organization Science 20 (2), pp. 281-293.

Amit, R. and P. J. H. Shoemaker (1993), Strategic assets and organizational rent, Strategic Management Journal 14, pp. 33-46

Andreu, R. and C. Ciborra (1996), Organizational learning and core capabilities development: The role of IT, Journal of Strategic Information Systems 5, pp. 111-127.

Anthony, R. N. (1960), The Trouble with Profit Maximization: It Is Too Difficult, It Is Unrealistic, It Is Immoral, Harvard Business Review 38 (6), pp. 126-134.

Barney, J. (1991), Firm resources and sustained competitive advantage, Journal of Management 17 (1).

Bellman, R. (2003), Dynamic Programming, Dover Publications.

Bertsekas, D. (2008), Dynamic Programming and Optimal Control, Athena Scientific.

Canals, J. (2010), Rethinking the Firm's Mission and Purpose, European Management Review 7, pp. 195-204.

Choi, J. and H. Wang (2009), Stakeholder relations and persistence of corporate financial performance, Strategic Management Journal, 30, pp. 895-907.

Chugh, L. and J. Meador (1984), The Stock Valuation Process: The Analyst's view, Financial Analysts Journal 40 (6), pp. 41-48

Chung, K. L. (1982), Lectures from Markov Processes to Brownian Motion, Springer.

Coen, C. A. and C. A. Maritan (2011), Investing in Capabilities: The Dynamics of Resource Allocation, Organization Science 22 (1), pp. 99-117

Coplestone, F. (1994), History of Philosophy, Vol. 7, Image Books.

Davis, J., K. Eisenhardt and C. Bingham (2007), Developing theory through simulation methods, Academy of Management Review 32 (2), pp. 480-499

Davis, J., K. Eisenhardt and C. Bingham (2007), Optimal Structure, Market Dynamism, and the Strategy of Simple Rules, Administrative Science Quarterly 54 (2), pp. 413-452.

Diecrickx, I. and K. Cool (1989), Asset stock accumulation and sustainability of competitive advantage, Management Science 35 (12), pp. 1504-1511.

DiMaggio, P. J. and W. W. Powell (1983), The iron cage revisited: Institutional isomorphisms and collective rationality in organizational fields, American Sociological Review 48, pp. 147-160.

Giancola, F. L. (2011), Examining the job itself as a source of employee motivation, Compensation \& Benefits Review 43 (1), pp. 23-29. 
Gilbert, N. (2008), Agent Based Models (Quantitative Applications in the Social Sciences), SAGE Publications.

Gosavi, A. (2010), Simulation-Based Optimization: Parametric Optimization Techniques and Reinforcement Learning, Kluwer Academic Publications.

Gottschalg, 0. and M. Zollo (2007), Interest Alignment and Competitive Advantage, Academy of Management Review 32 (2), pp. 418-437.

Harrison, J. et al. (2007), Simulation modeling in organizational and management research, Academy of Management Review 32 (4), pp. 1229-1245.

Haykin, S. (2009), Neural Networks and Learning Machines, Pearson-Prentice Hall.

Hekman, D. R., G. A. Bigley, H. K. Steensma and J. F. Hereford (2009), Combined effects of organizational and professional identification on the reciprocity dynamic for professional employees, Academy of Management Journal 52 (3), pp. 506-526.

Heyman, D. P. and M. J. Sobel (2003), Stochastic Models in Operations Research, Dover Publications.

Hurrion, R. D. (1993), Representing and Learning Distributions with the Aid of a Neural Network, The Journal of the Operational Research Society 44, pp. 1013-1023

Jensen, M. (2000), Value Maximization, Stakeholder Theory and the Corporate Objective Function, in M. Beer and N. Nohria, (eds.), Breaking the Code of Change, Boston, Harvard Business School Press, Also in Journal of Corporate Finance Fall 2001.

Kahneman, D. and A. Tversky (Eds.) (2000), Choices, Values and Frames, Cambridge University Press.

Klein, S. (1996), Learning: Principles and Applications, McGraw-Hill.

Kuipers, B. (1994), Qualitative Reasoning, Modeling and Simulation with incomplete Knowledge, MIT Press.

Lindenberg, S. (2001), Intrinsic Motivation in a New Light, Kyklos 54 (2/3), pp. 317-342.

March, J. G. (1991), Exploration and Exploitation in Organizational Learning, Organization Science 2 (1), pp. 71-87.

Meadows, D. H. (2008), Thinking in Systems: A primer, Chelsea Green Publishing.

Miller, J. H. and S. E. Page (2007), Complex Adaptive Systems: An Introduction to Computational Models of Social Life, Princeton University Press.

Pearl, J. (1988), Probabilistic reasoning in intelligent systems: Networks of plausible inference, Morgan Kauffman.

Pérez López, J. A. (1993), Fundamentos de la dirección de empresas, Madrid, Rialp.

Riverola, J. and B. Cuadrado (2008), Arte y oficio de la simulación, EUNSA.

Rosanas, J. (2008), Beyond Economic Criteria: A Humanistic Approach to Organizational Survival, Journal of Business Ethics, DOI 10.1007/s10551-006-9341-9ld. 
Rubinstein, A. (1997), Modeling Bounded Rationality, Boston, Mass., MIT Press

Ryan, R. M. and E. L. Deci (2000), Intrinsic and Extrinsic Motivations: Classic Definitions and New Directions, Contemporary Educational Psychology 25, pp. 54-67.

Saleh, S. and J. Hyde (1969), Intrinsic vs. Extrinsic Orientation and Job Satisfaction, Occupational Psychology 43, pp. 47-53.

Senge, P. (2000), The Puzzles and Paradoxes of How Living Companies Create Wealth, in M. Beer and N. Nohria, (eds.), Breaking the Code of Change, Harvard Business School Press.

Shuck, B. and K. Wollard (2010), Employee engagement and HRD: A seminal review of the foundations, Human Resource Development Review 9 (1), pp. 89-110.

Simon, H. (1955), A Behavioral Model of Rational Choice, Quarterly Journal of Economics 69 (1), pp. 99-118.

Simon, H. A. (1983), Reason in Human Affairs, Stanford, Cal., Stanford University Press.

Simon, H. A. (1997), Administrative Behavior, Fourth edition, New York, The Free Press.

Taylor, H. M. and S. Karlin (1998), An Introduction to Stochastic Modeling, Third Edition, Academic Press.

Teece, D., G. Pisano and A. Shuen (1990), Firm capabilities, resources and the concept of corporate strategy, Consortium on Competitiveness and Cooperation WP \#90-9, U. of California at Berkeley, Center for Research on Management, Berkeley, CA.

Tirole, J. (1988), The theory of industrial organization, The MIT Press.

Wagner, H. (1995), Global Sensitivity Analysis, Operations Research 43, pp. 948-969.

Welch, J. (2009), Jack Welch Elaborates: Shareholder Value, Business Week, March 16, 2009.

Wernerfelt, B. (1984), A resource-based view of the firm, Strategic Management Journal 5, pp. 171-180.

Zollo, M. and E. Freeman (2010), Re-thinking the firm in a post-crisis world, European Management Review 7, pp. 191-194. 